\title{
La traición bien acertada. Digitalización pública de obras sin derechos
}

\author{
Por José Antonio Millán
}

\begin{abstract}
Resumen: En el pasado, las bibliotecas proporcionaban obras para la investigación y también nuevos proyectos para las editoriales. La creciente existencia de copias digitales facilitará los usos privados y docentes, pero debería también alimentar proyectos editoriales comerciales. Sería paradójico que la digitalización estuviera en la práctica sacando del dominio público obras que estaban en él.

Palabras clave: Digitalización, Bibliotecas, Dominio público, Editoriales

Title: Well-meaning treachery. Public-funded digitisation of works free of rights

Abstract: In the past, libraries provided works for research and also new projects for publishing houses. The growing existence of digital copies will facilitate educational and private uses, but should also contribute to publishing projects. It would be paradoxical if digitisation were, in practice, to remove from the public domain works that had previously been in it.
\end{abstract}

Keywords: Digitisation, Libraries, Public domain, Publishing houses.

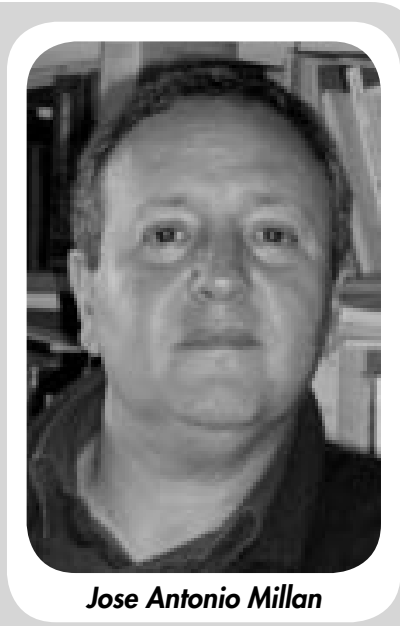

Millán, José Antonio. "La traición bien acertada. La digitalización pública de obras sin derechos”. En: El profesional de la información, 2007, marzo-abril, v. 16, n. 2, pp. 151-154.

DOI: 10.3145/epi.2007.mar.08

NUESTRAS BIBLIOTECAS, nuestras instituciones públicas están llenas de obras no protegidas (porque nunca han tenido derechos de autor), o en el dominio público (porque sus derechos han vencido). Para simplificar, usaré "obras sin derechos" para abarcar ambas categorías, y para simplificar también me centraré en los libros (aunque en idéntica situación se encuentren grabaciones, partituras, obras plásticas...).

Desde hace unos pocos años ha habido frecuente dinero público para proyectos de digitalización de libros y otros documentos. Y recientemente, a través de los acuerdos de Google Libros, también es posible que las instituciones consigan digitalizaciones por acuerdo con empresas privadas. Es, por tanto, importante saber qué estatus tienen estas obras.

En principio, la existencia de estos facsímiles digitales -copias en soporte electrónico de los documentos en papel-debería servir para mejorar la difusión de las obras que las bibliotecas tienen en custodia, pues los ficheros se pueden copiar indefinidamente, a nulo coste y sin pérdida de calidad, y pueden llegar a cualquier lugar. Para analizar su estatuto actual puede valer la pena remontarnos a su prehistoria.

Antes de la digitalización, ¿qué se podía hacer con los libros públicos de una biblioteca (aparte de leerlos)? Bueno: uno podía ir a la sala, pedir el ejemplar manuscrito o impreso de una obra (por ejemplo, de la comedia de Lope de Vega La traición bien acertada) y transcribirla en un cuaderno para luego regularizar la ortografía, compararla con otras versiones y hacer, en fin, todas las operaciones conducentes a publicarla en forma de libro. La obra seguiría sin tener derechos, pero el trabajo de transcribir, corregir, etc., habría generado nuevos derechos para el autor de la edición. Para publicar ésta no hacía falta el permiso de la biblioteca, aunque, si el autor era como se debe, indicaría que su edición se basaba en el ejemplar preservado en la Biblioteca XX, con la signatura YY, y con mucha frecuencia agradecería al bibliotecario $\mathrm{ZZ}$ su ayuda profesional.

¿Qué ganaba la biblioteca con esto? Nada, salvo cumplir su función de preservación y difusión de la cultura, y la propaganda de ver su nombre ligado a una obra. ¿Qué ganaba el autor de la edición? Fama, créditos académicos y un porcentaje sobre el precio de venta. ¿Qué ganaban la editorial, el distribuidor, el librero?: sus respectivos márgenes comerciales. ¿Qué ganaba el público?: el acceso a una obra de Lope desconocida o insuficientemente editada. ¿Qué ganaba la cultura general?: el aumento de su conocimiento de la literatura del XVII, a través de la disponibilidad de una obra no sólo a la venta en librerías, sino también accesible para lectura y préstamo en muchas bibliotecas.

Supongamos ahora que para hacer esta edición de Lope (antes de la era digital) el investigador hubiera encargado a la biblioteca una reproducción del ejemplar, para trabajar tranquilamente en su despacho. $\mathrm{La}$ biblioteca le cobraría esta reproducción fotográfica o la fotocopia (por 
el trabajo de la persona que había buscado el libro y abierto cada una de sus páginas ante la máquina, más la amortización de los equipos empleados). Esta operación por lo general no enriquecía a las bibliotecas, sino que les planteaba numerosos problemas de gestión y facturación, pero formaba parte de sus deberes de difusión.

A partir de esa reproducción fotográfica se podía hacer no sólo la transcripción, sino también una edición facsímil. En principio, para ella no habría por qué pedir permiso a la institución que custodiaba la obra. Ésta no tenía derechos y la fotografía tampoco había generado derechos de autor, por no tratarse de lo que la ley llama una "obra fotográfica" (con la creatividad que se supone en toda obra). Y sin embargo, uno se encontraba frecuentemente con instituciones que hacían pedir "permiso" para esta edición.

\section{$Y$ ya por fin llegamos a la era digital}

Los proyectos de digitalización han supuesto una inversión pública, y no precisamente pequeña, en copias digitales de infinidad de obras sin derechos (nos centraremos ahora en el caso más común, el de ficheros digitales que son sólo imagen de las páginas; la conversión de la obra en texto buscable introduce una compleja problemática paralela, que habrá que tratar en otro momento).

Las bibliotecas y otras instituciones públicas han hecho que estas obras sean accesibles en línea. Un primer requisito sería que dieran acceso total a estos ficheros de las obras, y en la mejor definición (o resolución) en que se tengan. No se puede justificar que los catalógos no ofrezcan acceso pleno y claro a todas sus digitalizaciones (incluso procedimientos como el registro previo del usuario son escasamente defendibles). Respecto al uso de estos ficheros no creo que nadie se opusiera a que un usuario privado lea las obras, ni a que se impriman y repartan copias para su uso docente. Y sin embargo algunos discutirán que se puedan incorporar libremente a otra web o que puedan dar lugar sin más trámite a una nueva edición.

Mi tesis, sin embargo, es que estas obras deberían poder ser reproducibles sin ningún límite, respetando la mención de la institución de origen ( $\mathrm{u}$ otras condiciones razonables, que podrían expresarse en una licencia aneja). Y que esta reproducción podría legítimamente servir tanto para usos privados como para uso comercial. Es decir: cualquier editor debería poder publicar tanto el facsímil como la transcripción y edición de La traición bien acertada (bajo la forma de libro tradicional, como libro electrónico para PDA, o en la forma que sea), a partir de la copia digital almacenada en los servidores de la institución, sin necesidad de obtener permiso alguno ni abonar ninguna tasa.

Pero eso es un uso comercial (se espantarán algunos), no privado ni, por ejemplo, didáctico. ¿Por qué una empresa debería hacer dinero vendiendo una obra sin derechos, cuyo ejemplar tiene custodiado la biblioteca XX? Por cierto, nuestro mundo cultural padece una curiosa hipocresía que hace que -en una sociedad absolutamente dominada por el dinero- surja un mohín de desprecio cuando éste aparece... La respuesta es que esa empresa dará servicio al lector (que leerá un $e$-book bien formateado, o un bello volumen, en vez de un conjunto de folios impresos), y aparte de ganar ella dinero, ganará también toda la cadena comercial, y además la cultura se difundirá... No se me ocurre mejor panorama que el de decenas de editoriales sacando al mercado nuestros tesoros bibliográficos, porque la digitalización llevada a cabo por una institución pública lo ha hecho posible.

De hecho ya hay experiencias de cómo influye en la difusión de una obra su libre distribución, in- cluyendo la comercial. Las fotografías de la NASA han alcanzado la popularidad que tienen gracias a esta licencia de distribución ilimitada. Pero hay más: se ha estudiado también cómo influye este aspecto en la creación de empleo y riqueza: los datos producidos por instituciones públicas de Estados Unidos (por ejemplo, meteorológicos), que son plenamente reutilizables por las empresas, han creado un sector privado diez veces mayor que el europeo, sometido a notables restricciones (para un resumen véase Javier Candeira, "La gratuidad de los datos públicos como activador económico en los Estados Unidos"):

http://ciberderechos.barrapunto. com/

article.pl . sid =06/03/23/1951256

\section{¿Digitalizar para entorpecer la difusión?}

Esta constatación coincide con un nuevo posicionamiento de los ministerios de cultura europeos $(E l$ país, 14/11/2006: "La UE respalda la creación de una biblioteca europea"). Ahora parece que lo que interesa más es lo económico.

El aspecto económico de la cultura fue otro de los aspectos que discutieron ayer los ministros europeos en Bruselas:

"Si en algo podemos competir en Europa es en cultura. La cultura genera miles de empleos y mueve miles de millones de euros", explicaron fuentes diplomáticas. El sector de la cultura contribuyó en 2003 en un 2,6\% al PIB de la Unión Europea. Los 25 coincidieron ayer en que la cultura debe dejar de ser considerada como "algo que tiene que ver con los valores", según las fuentes oficiales españolas, y debe sin embargo tenerse en cuenta la contribución de la cultura al crecimiento económico y a la creación de empleo.

Bien: habrá que ver si realmente se quiere fomentar el "crecimiento económico" (favoreciendo la apa- 


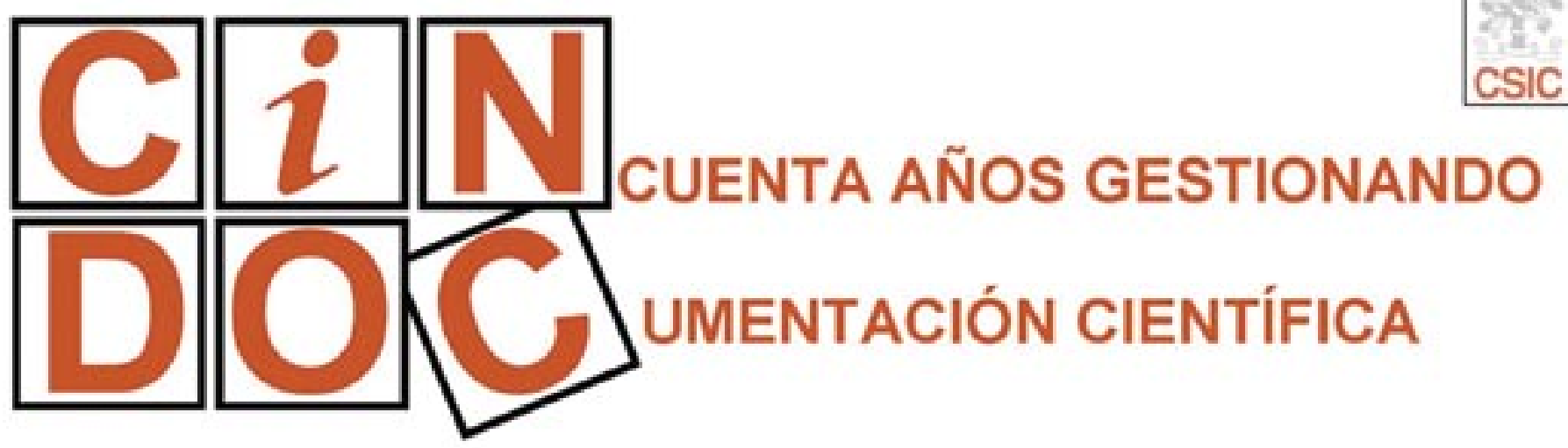

\section{Bases de Datos CSIC: Lo nuestro son los contenidos}

EI CSIC produce desde 1971 tres bases de datos bibliográficas con referencias de los articulos publicados en revistas cientificas españolas y en otros documentos científico-técnicos
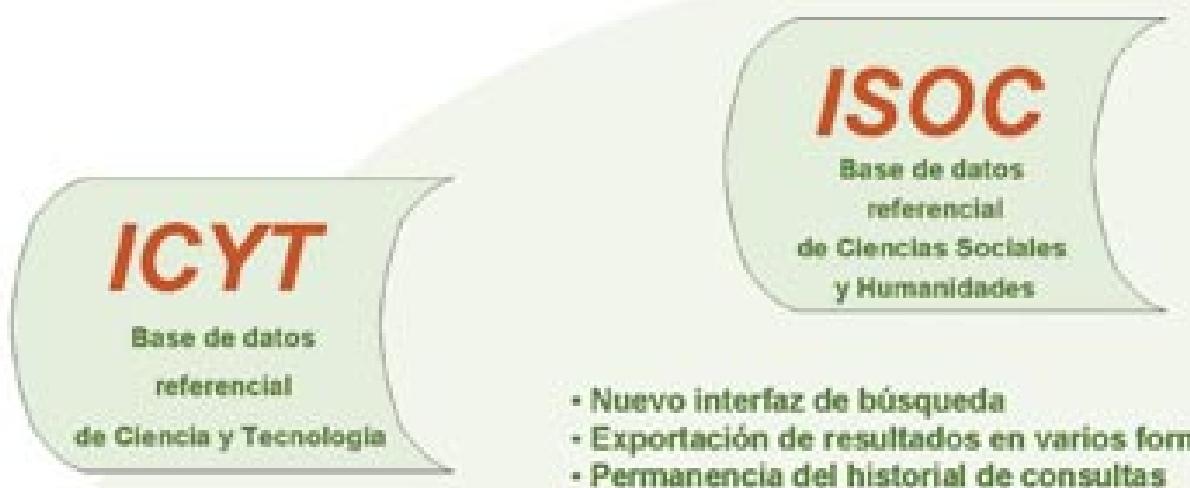

- Nuevo interfaz de búsqueda

- Exportación de resultados en varios formatos

- Permanencia del historial de consultas

- Disponibilidad de algunos documentos a texto completo

- Acceso gratuito a Sumarios

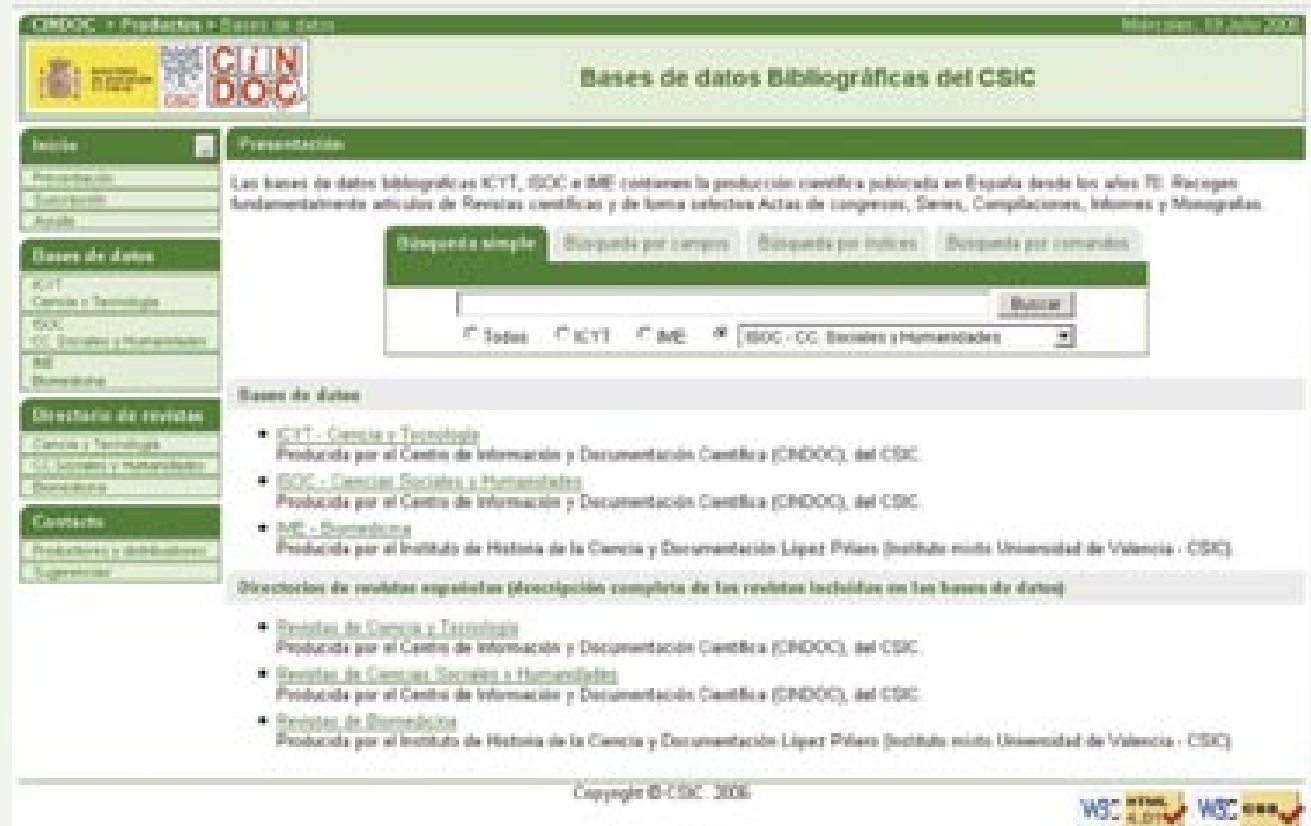

wo:ine wocest

Consulte condiciones de suscripción en nuestro web

http://www.cindoc.csic.es 
rición de pequeñas empresas editoriales al servicio de la difusión de nuestro patromonio bibliográfico), o si se va a intentar elevar barreras artificiales para que sólo algunos tengan acceso al negocio.

Recapitulemos: estamos ante estas instituciones públicas que han digitalizado obras. Y tenemos a una empresa que quiere producir facsímiles impresos o digitales a partir de ellas. Por supuesto, podría cargársele una tarifa en concepto de los costes iniciales de digitalización, más la parte proporcional de alojamiento en un servidor. Aunque creo que ésta sería una estrategia mezquina por parte de los poderes públicos, y contraria a sus fines confesos de difusión del saber. Y sin embargo, se ven situaciones aún peores.

Los procesos de digitalización podrían ser entendidos (y hay quien desde el sector público defiende esta postura), como la creación de una obra derivada, lo que implicaría que en el proceso se han generado nuevos derechos de propiedad inte- lectual. O incluso se puede considerar que la versión digital puesta en la Red constituye una publicación, que igualmente generaría derechos. En la práctica, muchas veces las instituciones que han digitalizado se comportan como si detentaran la propiedad de los objetos digitales, y parece que a los bibliotecarios y otros profesionales les cabrá la difícil misión (que no sé si quieren) de erigirse en jueces de la pertinencia o no de esta o aquella edición hecha a partir de sus fondos.

Puestas así la cosas, nos encontramos ante una paradoja terrible, pero que mucho me temo refleja a la perfección la ideología de nuestras instituciones públicas (como si pensaran: “¿qué se han creído, que cualquiera puede venir y publicar nuestras obras?"). La digitalización, el mayor dispositivo de divulgación de la cultura jamás emprendido por el hombre, ¿servirá en la práctica para generar derechos para obras de nuestro acervo cultural que no los tenían, poniendo así trabas a las empresas que podrían difundirlo?

El patrimonio bibliográfico español en instituciones públicas es riquísimo, y la ideología pro-digital imperante en los últimos años ha impulsado notables políticas de digitalización, realizada con fondos públicos. Ha llegado el momento en que los poderes públicos digan claramente qué es lo que creen que podemos hacer con las obras sin derechos que nuestras instituciones han digitalizado por nuestro impulso y con nuestro dinero. Ah! y que lo digan con suficiente margen para que se cree un debate público sobre ello.

(Agradezco a Ana Nistal, Miguel Jiménez, Patricia Riera y a varios comunicantes del Blog del Futuro del Libro sus aportaciones a este debate, así como a Javier Candeira y a quienes debatieron temas afines en Barrapunto).

\section{José Antonio Millán}

privado@jamillan.com

http://jamillan.com 